\title{
Implementação de mídias em dispositivos móveis: um framework de aplicação em grande escala na educação a distância
}

\author{
Implementation of media in mobile devices: a \\ framework for a large-scale application in distance \\ education
}

\author{
Ana Luisa Mulbert \\ Universidade do Sul de Santa Catarina (Brasil) \\ Alice T. Cybis Pereira \\ Universidade Federal de Santa Catarina (Brasil)
}

\section{Resumo}

Ouso intensivo das tecnologias dainformação têm criado condições para o desenvolvimento um novo modo de mediação educacional chamado de mobile learning (m-learning). Dado que há ainda pouco conhecimento sobre as práticas de m-learning em larga escala e em nível institucional, esse trabalho teve por objetivo desenvolver um framework para apoiar a implementação de mídias para dispositivos móveis no ensino formal, integrado à educação superior a distância e com requisitos de escalabilidade e sustentabilidade. Para a execução desse estudo adotou-se um processo de pesquisa baseado na abordagem da Design-Based Research, que é um tipo de pesquisa que se desenvolve em contextos reais e concentrase no desenho e teste de intervenções educacionais em parceria com profissionais da área de aplicação. Na fase de desenvolvimento do processo de pesquisa tomou-se um conjunto de decisões que estabeleceram o delineamento da iniciativa, desenvolveu-se uma mídia e avaliou-se o processo de sua implementação. Em seguida, adotou-se a mídia em um contexto real de aprendizagem e avaliou-se a iniciativa na perspectiva dos estudantes. O framework formulado a partir da experimentação realizada é apresentado por meio de um diagrama representativo das principais fases e atividades de implementação e de um conjunto de princípios de design que orientam a execução do processo de implementação de mídias educacionais móveis. As fases de implementação e seus respectivos princípios versam sobre: (a) o delineamento e delimitação da implementação, (b) o desenho e produção da mídia e (c) a entrega e disseminação da mídia no ambiente de aprendizagem.

Palavras chave: tecnologia da informação; educação a distância; educação tecnológica; m-learning; livro digital; ebook. 


\begin{abstract}
The intensive use of information Technologies has created conditions for the development of a new mode of educational mediation called mobile learning. Considering that there is still little knowledge about the practices and experiences of mobile learning on a large scale and at na institutional level, this study aimed to develop a framework to support the implementation of mobile media in formal teaching, integratedin to distance education programs and with scalability and sustainability requirements. A research process was adopted, based on the Design-Based Research approach, which is a type of research that is developed in real contexts and focused on the design and tests of educational interventions in partnership with professionals of the application area. At the development phase of the research process, a series of decisions were made that established the outline of the initiative, developed a mobile media and evaluated the process. Then the mobile media was applied in a real learning context and the initiative was evaluated from the students' perspective. The framework is presented through a representative diagram of the main stages and implementation activities, as well as a set of design principles that guide the implementation process of the educational mobile media. Implementation stages and their principles deal with: (a) implementation outline and demarcation, (b) design and production of the media and (c) delivery and dissemination of the media in the learning environment.
\end{abstract}

Keywords: information technology; distance learning; technological education; m-learning; digital book; ebook.

As atividades humanas e a interação social dos indivíduos têm sido significativamente afetadas por um ambiente de computação ubíqua e sem fio, proporcionando novos hábitos e ritmos à vida social, marcados pela mobilidade, novas formas de usar os espaços públicos e novas possibilidades de explorar fontes de informação e comunicação (New Media Consortium, 2016). Segundo Santaella (2013), essas práticas estão construindo um novo espaço de misturas inextricáveis entre o virtual (ciberespaço) e os ambientes físicos que nossos corpos habitam, formando assim espaços híbridos. Tais espaços são também móveis, se constituem em múltiplos espaços em um mesmo espaço e desafiam os sentidos de localização, permanência e duração.

Ao mesmo tempo, emerge nova geração de nativos digitais, que se caracteriza pela conectividade frequente, possui hábito de obter imediata resposta às suas demandas e está acostumada ao imediato acesso à informação em qualquer lugar e a qualquer momento (Akçayir, Dündar e Akçayir, 2016; Hutchison e Tine Cao, 2008; Jones, Ramanau, Crosse e Healing, 2010). Os atributos dessa geração evidenciam um perfil de estudante com novos hábitos de aprendizagem, que demandam por novas formas de construir conhecimento.

Segundo o New Media Consortium (2016), o acesso a recursos, redes de comunicação e mídias sociais tem contribuído para aumentar expectativas dos indivíduos de usufruir de oportunidades de aprendizagem baseadas na mobilidade, com a possibilidade de trabalhar, aprender e estudar quando e onde desejar. 
Em tal cenário criam-se condições para o desenvolvimento de mobile learning (m-learning), que se refere ao uso educacional de dispositivos móveis e portáteis, como tablets, smartphones, consoles de jogos e outros que viabilizam práticas de compartilhamento da informação e do conhecimento em variadas mídias, em qualquer lugar e a qualquer momento (Traxler e Vosloo, 2014).

Está evidente que o desenvolvimento de práticas pedagógicas que exploram a mobilidade é assunto de relevância para as instituições de ensino que pretendem manter-se em sintonia com as novas possibilidades viabilizadas pelas tecnologias educacionais emergentes. Por outro lado, a incorporação de tecnologias inovadoras não é um processo simples para as instituições de ensino. Segundo o New Media Consortium (2016), fatores como resistência à mudança ou percepções equivocadas limitam a implementação da inovação em contextos escolares. Então, iniciativas de m-learning, apesar de se apresentarem como tendência e de haver um público aparentemente receptivo à sua adoção, têm obstáculos a serem superados no ambiente escolar formal.

Na literatura científica existem variadas experiências publicadas sobre o uso de mídias educacionais para dispositivos móveis, mas a maioria delas é de alcance limitado a pequenos grupos. Em relação à implementação em larga escala, Wingkvist e Ericsson (2009) apontam que é necessário ainda compreender melhor as ferramentas e recursos necessários para a adoção massiva de m-learning em âmbito institucional. Segundo eles, a adoção massiva por parte das instituições de ensino precisa conjugar requisitos de sustentabilidade e escalabilidade, que garantam a manutenção das iniciativas no longo prazo.

Nesse contexto, o presente trabalho apresenta os resultados de uma iniciativa de implementação de mídias educacionais para dispositivos móveis (que denominamos de mídia móvel), no contexto da educação superior a distância, em larga escala e com requisitos de sustentabilidade de longo prazo. Nessa iniciativa desenvolveu-se o livro didático eletrônico em formato EPUB ${ }^{1}$, adaptado para uso em dispositivos móveis. A partir dessa iniciativa extraiu-se o conhecimento alcançado para propor um framework de apoio a implementação de iniciativas similares. Esse framework representa um conjunto de recomendações, organizadas na forma de um diagrama, com fases e atividades de implementação das mídias, e de um conjunto de princípios de design para a iniciativa. O desenvolvimento da pesquisa segue os pressupostos da abordagem da Design-Based Research, explicados a seguir.

\section{ABORDAGEM METODOLÓGICA E O PROCESSO DE PESQUISA}

A Design-Based Research (DBR) é um paradigma de pesquisa emergente que se desenvolve em contextos reais e concentra-se no desenho e teste de intervenções educacionais significativas e práticas (Anderson e Shattuck, 2012). Esse tipo de pesquisa busca atender a necessidade de desenvolver contextos, frameworks, ferramentas e modelos pedagógicos consistentes e comprometidos com teorias 
pedagógicas emergentes (Barab e Squire, 2004). Nesse contexto, Anderson e Shattuck (2012) destacam que a DBR é um paradigma de pesquisa capaz de apoiar criação de conhecimentos sobre o desenvolvimento, organização e suporte de ambientes de aprendizagem inovadores.

Wang e Hannafin (2005) definem a DBR como uma abordagem metodológica sistemática e flexível que busca aperfeiçoar as práticas de ensino através da análise, design, desenvolvimento e implementação iterativa, baseada na colaboração, em contextos reais, entre pesquisadores e praticantes, capaz de levar à construção de teorias e princípios de design sensíveis ao contexto. O pragmatismo da DBR é característica fundamental que revela seu compromisso com a solução de problemas concretos. Mas a DBR não está somente preocupada com a investigação dos resultados de uma intervenção, está também, e principalmente, interessada na compreensão do design da iniciativa, na compreensão de seus desafios de implementação e dos processos de criação e gerenciamento da intervenção (Anderson e Shattuck, 2012). A intenção da DBR, mais do que gerar artefatos ou programas específicos, é gerar modelos que apoiem a inovação em contextos educacionais. Isso é obtido pela colaboração entre pesquisadores e participantes ligados à implementação que, juntos, desenvolvem a compreensão do problema, estabelecem o design da solução e a implementam, seguindo juntos ao longo da iniciativa (Wang e Hannafin, 2005).

O processo de desenvolvimento da pesquisa compreende múltiplas iterações em ciclos de aperfeiçoamento da solução proposta. Segundo Matta, Silvae Boaventura (2014), a abordagem iterativa e de refinamento de soluções práticas talvez seja a característica mais marcante da DBR. À medida que as iterações acontecem há a possibilidade de adaptar a proposta de solução anteriormente encontrada, promovendo seu refinamento.

Barab e Squire (2004) apontam como atributos próprios da DBR: (a) a flexibilidade existe ao longo de toda a intervenção, pois a revisão do design pode acontecer em qualquer etapa; (b) o contexto é considerado como parte integrante da iniciativa e não mera variável externa, e (c) os participantes são concebidos como cointegrantes da investigação e não apenas como sujeitos investigados.

Seguindo os princípios da DBR, vários autores fizeram propostas de processos de pesquisa que partilham a mesma lógica. O processo inicia pela análise de problemas práticos seguida pelo desenvolvimento de soluções e pela avaliação da solução proposta, que se desenvolve e refina repetidamente em várias iterações. A fase final do processo culmina com a elaboração de "princípios de design", resultantes da reflexão sobre o desenho da solução e da explicitação dos princípios que embasaram a iniciativa. Esses princípios podem servir como guia para outros praticantes que, em iniciativas similares, podem reiniciar o processo e promover seu refinamento (Reeves, 2000). A Figura 1 sintetiza esse processo. 
Figura 1. Processo de desenvolvimento da Design-Based Research

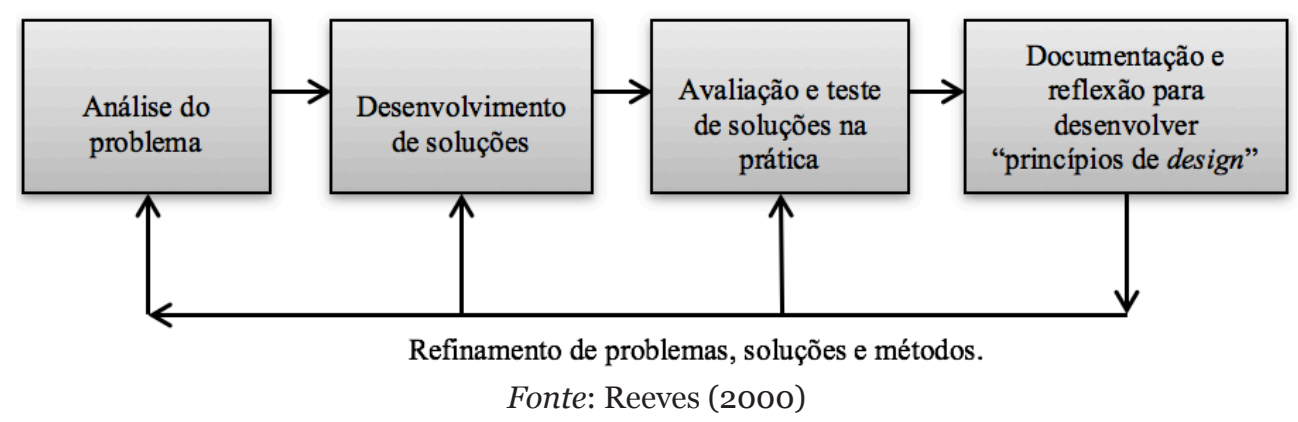

Nota-se que nesse processo não há previsão de fim, já que pode ter vários ciclos de refinamento. Segundo Anderson e Shattuck (2012), o desafio do pesquisador está em identificar quando finalizar e dar-se por satisfeito com o ciclo evolutivo da iniciativa. Caberá ao pesquisador consolidar resultados quando considerar que são suficientemente significativos para serem partilhados.

\section{DESENVOLVIMENTO DA PESQUISA}

Para alcançar os objetivos desse estudo adotou-se uma abordagem de métodos mistos de pesquisa. Segundo Creswell (2007), a abordagem por métodos mistos é aquela que reúne dados quantitativos e qualitativos que, em alguma das fases da pesquisa, são integrados entre si. A abordagem qualitativa foi utilizada na fase de desenvolvimento de soluções, em que os pesquisadores associaram-se aos especialistas educacionais para tomar decisões sobre a iniciativa e também para avaliar seu processo de desenvolvimento. As abordagens quantitativa e qualitativa foram utilizadas, juntas, na fase de avaliação e testes, em que se fez a entrega da mídia móvel ao estudante e na qual aplicou-se um questionário com questões fechadas e abertas.

Os dados qualitativos de todas as fases do estudo foram tratados por meio de análise de conteúdo, com apoio do software Atlas.ti. Essa ferramenta oferece recursos para sistematizar dados pouco estruturados. Possui um ambiente intuitivo com recursos para gerenciar, extrair, comparar, explorar e reorganizar partes dos dados consideradas significativas por meio de processos de codificação (Friese, 2013). Dados quantitativos e qualitativos foram articulados entre si, em uma análise interpretativa, para extrair o sentido do fenômeno estudado, visando descrever e interpretar a experiência dos estudantes com a mídia móvel e identificar aspectos que podem contribuir para a formulação dos princípios de design de iniciativas similares. 
Dado o grande volume de dados coletados na pesquisa e da falta de espaço nesse artigo para sua detalhada descrição, apresenta-se aqui os resultados sintetizados. A análise completa dos dados, bem como a descrição pormenorizada da iniciativa e de seus artefatos podem ser obtidos em Mulbert (2014).

Tomando o processo de pesquisa anteriormente descrito, executou-se cada uma de suas fases, conforme Quadro 1, descritas na sequência.

Quadro 1. Síntese das fases de investigação conforme o processo de pesquisa adotado

\section{FASES DO PROCESSO DE} PESQUISA

\begin{tabular}{|c|c|c|}
\hline \multicolumn{2}{|c|}{$\begin{array}{l}\text { Análise do problema de } \\
\text { pesquisa }\end{array}$} & $\begin{array}{l}\text { Estudo dos fundamentos teóricos-científicos e } \\
\text { levantamento das características do contexto } \\
\text { ambiental que moldam a iniciativa. }\end{array}$ \\
\hline \multirow{2}{*}{$\begin{array}{l}\text { Desenvolvimento } \\
\text { de soluções }\end{array}$} & $1^{0}$. Ciclo & $\begin{array}{l}\text { Delimitação da iniciativa por um grupo de } \\
\text { especialistas, com primeiras decisões sobre } \\
\text { requisitos e direcionamentos para alcançar larga } \\
\text { escala. }\end{array}$ \\
\hline & $2^{\circ}$. Ciclo & $\begin{array}{l}\text { Desenvolvimento da mídia móvel, dos artefatos } \\
\text { e processos complementares para entrega aos } \\
\text { estudantes. }\end{array}$ \\
\hline \multicolumn{2}{|c|}{ Avaliação e teste de soluções } & $\begin{array}{l}\text { Aplicação da mídia em contexto real de } \\
\text { aprendizagem e avaliação pela ótica dos estudantes. }\end{array}$ \\
\hline \multicolumn{2}{|c|}{$\begin{array}{l}\text { Documentação e reflexão para } \\
\text { desenvolver os "princípios de } \\
\text { design" }\end{array}$} & $\begin{array}{l}\text { Consolidação dos resultados intermediários em um } \\
\text { framework e redação de princípios de design da } \\
\text { iniciativa. }\end{array}$ \\
\hline
\end{tabular}

\section{Análise do problema de pesquisa}

$\mathrm{Na}$ análise do problema realizou-se a pesquisa bibliográfica sobre o tema m-learning e do levantamento de iniciativas publicadas de implementação em larga escala. Os estudos teóricos propiciaram melhor entendimento do tema e do problema e subsidiaram a elaboração das próximas atividades da pesquisa. Nessa fase também estudou-se as características da instituição pesquisada.

A pesquisa foi desenvolvida em uma universidade comunitária brasileira a Universidade do Sul de Santa Catarina (UNISUL), que atua nas modalidades presencial e a distância. Suas atividades de EAD são desenvolvidas desde 2005 e contam com uma rede de 77 polos presenciais distribuídos em todas as regiões do Brasil. A Tabela 1 apresenta indicadores que caracterizam o contexto da iniciativa e a escala das operações institucionais. 
Tabela 1. Indicadores de EAD da instituição pesquisada

\begin{tabular}{|l|l|}
\hline \multicolumn{1}{|c|}{ Indicador } & \multicolumn{1}{c|}{ Nr. } \\
\hline Total de cursos de graduação em EAD & 32 \\
\hline Total de cursos de pós-graduação em EAD & 24 \\
\hline Total de disciplinas de graduação ofertadas a distância semestralmente & 540 \\
\hline Total de turmas de graduação ofertadas a distância semestralmente & 1.094 \\
\hline Total de alunos atendidos semestralmente & $\mathbf{2 4 . 0 9 6}$ \\
\hline Total de alunos atendidos em cursos EAD semestralmente & 10.257 \\
\hline
\end{tabular}

Fonte: Sistema acadêmico institucional

A fase seguinte da pesquisa, de desenvolvimento de soluções, foi dividida em dois ciclos, descritos a seguir.

\section{$1^{\text {o }}$ ciclo de desenvolvimento da solução: primeiras decisões dos especialistas}

No princípio da iniciativa um grupo de oito especialistas realizou diversas reuniões, de caráter exploratório, com a finalidade de estudar o potencial das tecnologias móveis aplicadas à EAD e avaliar como elas poderiam ser utilizadas em larga escala nas operações da instituição. Nesse período foram realizadas e gravadas seis reuniões, que totalizaram 8 horas e 39 minutos. O grupo de especialistas foi formado por professores, designers instrucionais, designers visuais e técnicos em produção de materiais didáticos. As gravações foram transcritas e tratadas por meio do software Atlas.ti, que possibilitou a sistematização e codificação das falas. Esse processo resultou na criação de um mapa (Figura 2), que representa visualmente o agrupamento dos temas identificados como importantes e que possibilitou a navegação pelos dados conforme seu conteúdo. Assim, dentro de um conjunto de dados complexos, volumosos e inicialmente confusos, foi possível identificar as primeiras decisões que delinearam a iniciativa, estruturadas em diferentes temas. Nesses dados identificou-se também as expectativas em relação à iniciativa, bem como incertezas e riscos associados. 
Figura 2. Mapeamento dos dados qualitativos no $1^{\mathrm{o}}$ ciclo de desenvolvimento

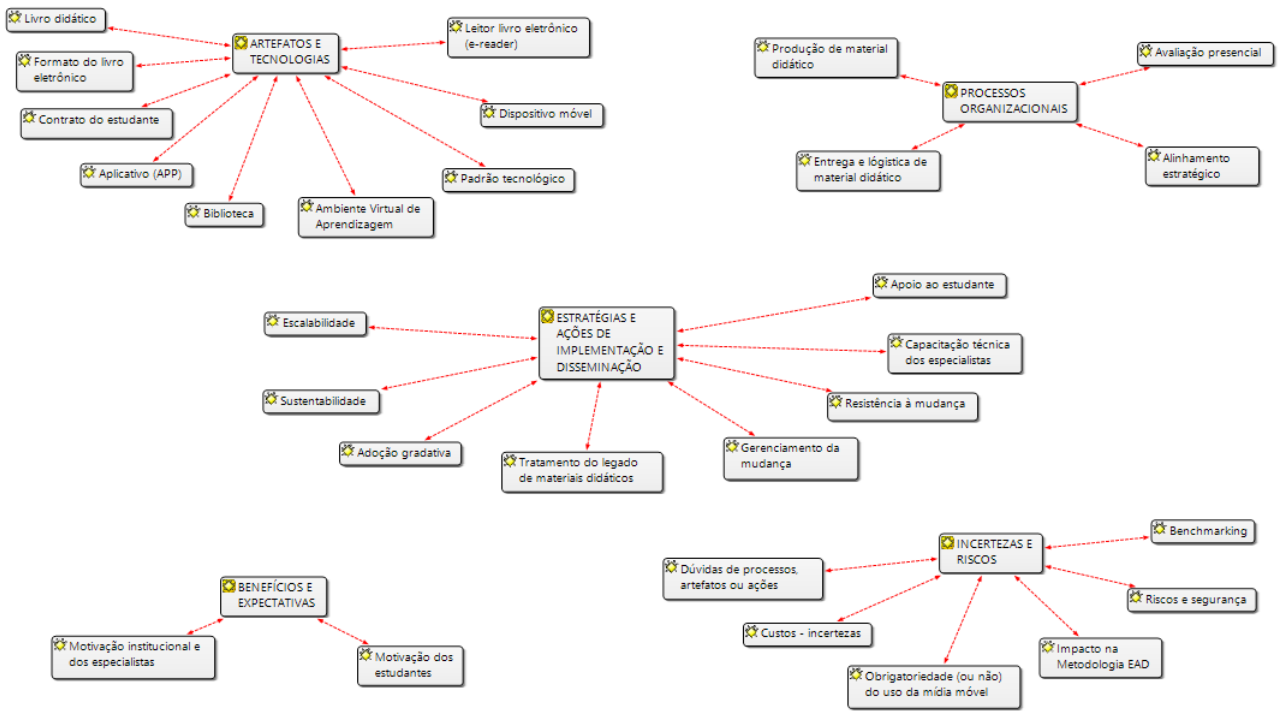

Sobre a mídia móvel decidiu-se que o artefato a ser implementado é o livro didático em formato EPUB (denominado como livro didático eletrônico) e que esse exige também como artefato complementar um software leitor para abrir a mídia no dispositivo. A nova mídia não deve substituir o livro impresso já costumeiramente ofertado aos estudantes. Além disso, para alcançar larga escala, a mídia móvel deve ser leve e operável em ampla gama de dispositivos de propriedade do próprio estudante. O uso da mídia móvel não deve ser obrigatório, mas deve ser estimulado por ações complementares de encorajamento.

Quanto aos processos organizacionais, concluiu-se que a adoção de uma mídia móvel deve gerar impacto significativo sobre os processos de produção dos materiais didáticos. A lógica do processo atual está orientada para a elaboração de livros impressos, de modo que atividades de diagramação, padrões visuais e recursos tecnológicos necessários precisam ser adaptados. Além disso, considerou-se que o mesmo processo deve contemplar a produção do livro impresso e de sua versão para dispositivo móvel, pois a interrupção da oferta do livro impresso foi considerada indesejável pelos prováveis impactos negativos decorrentes de rupturas com hábitos preestabelecidos. Os especialistas destacaram também que a convivência dos vários formatos de livro deve gerar limitações no desenho da versão móvel, pois se este também tem que ser imprimível, não será possível nele embarcar recursos multimídia. O grupo de especialistas concordou que a entrega da mídia móvel deve se dar pelo ambiente virtual de aprendizagem (AVA) institucional, pois esse é um mecanismo já consolidado para entrega de conteúdos digitais. 
Quanto às estratégias para alcançar larga escala, decidiu-se que as mídias móveis devem ser de fácil desenvolvimento para que processos organizacionais possam contemplar a conversão de um acervo de mais de 500 livros didáticos preexistentes na versão impressa. Concluiu-se também que a complexidade da iniciativa deriva-se mais da necessidade de escala e sustentabilidade do que de desafios tecnológicos. Isso porque as ações de desenvolvimento de livros eletrônicos, vistas individualmente, não se caracterizam com um processo de difícil domínio técnico. É o volume de trabalho envolvido que traz maior complexidade.

Para dar conta da escalabilidade os especialistas identificaram que a implementação deve ser gradativa, contemplando concomitantemente tanto a produção de novos materiais como também a conversão do acervo de materiais preexistentes. Também concluíram que a iniciativa exige mudanças organizacionais e traz maior complexidade aos processos, até que as mudanças sejam incorporadas à rotina. A fase de transição, até que todo o acervo seja convertido, exige esforço adicional de enfrentamento de prováveis resistências dos estudantes.

Nesse primeiro ciclo observou-se que o delineamento da iniciativa envolve um conjunto de decisões de natureza tecnológica, instrucional e organizacional. Que o avanço da iniciativa, até que alcance larga escala, depende de decisões críticas, que ao serem tomadas determinam caminhos e desdobramentos que estabelecem o perfil particular da iniciativa. Tais decisões são como encruzilhadas que estabelecem contornos únicos da iniciativa. Um exemplo disso é a decisão sobre a obrigatoriedade ou não de uso da mídia móvel pelo estudante, pois caso a mídia fosse de uso obrigatório o desenho dos próximos passos teria que ser diferente daquele adotado.

Nesse ciclo caracterizou-se também que dúvidas e incertezas são significativas no estágio inicial da implementação. A superação das incertezas depende da experimentação, que possibilitará a avaliação mais aprofundada dos impactos, da escalabilidade e sustentabilidade.

\section{$2^{0}$ ciclo de desenvolvimento da solução: a construção da mídia e dos recursos complementares}

No segundo ciclo de desenvolvimento os pesquisadores e especialistas elaboraram a mídia e desenharam a estratégia de entrega ao estudante. Nele buscou-se o detalhamento e operacionalização das decisões estratégicas tomadas no primeiro ciclo. A partir da vivência de construção da mídia pelos designers, buscouse compreender seu processo de desenvolvimento e avaliar impactos decorrentes sobre os processos organizacionais preexistentes. Com as reflexões e a aprendizagem alcançada nesse ciclo, colheu-se subsídios importantes para compor o framework almejado.

A implementação da mídia foi realizada por um grupo formado por um designer instrucional, um designer gráfico, um coordenador de designe os pesquisadores, que periodicamente tomaram decisões conjuntas e compartilharam atividades 
executadas individualmente. O designer instrucional fez a revisão do conteúdo do livro selecionado como alvo de implementação (já existente em impresso) de modo a adaptá-lo para a nova mídia. O designer gráfico fez o projeto visual e a diagramação para o formato EPUB. O coordenador de design contribuiu na tomada de decisões e suporte às tarefas individuais. Os pesquisadores contribuíram com as decisões e encarregaram-se da preparação da comunicação da mídia aos estudantes. Ao final desse ciclo procedeu-se sua avaliação em encontros com os envolvidos, que foram gravados, transcritos e seus resultados submetidos a procedimentos de análise de conteúdo, conforme já descrito.

Nesse segundo ciclo obteve-se, portanto, o livro didático de uma disciplina em formato EPUB e um vídeo de orientações de uso da nova mídia. Nas orientações aos estudantes destacou-se a necessidade de um programa leitor para manipular a mídia, os modos de carrega-la no dispositivo, além de uma mensagem motivadora de estímulo ao uso.

Na avaliação dos designers considerou-se que o padrão EPUB é apropriado para uso em variados dispositivos que, associado ao leitor, pode trazer ferramentas complementares de interação inexistentes na versão impressa (marcação, anotação e pesquisa, etc.). Outra descoberta importante é que a escolha do programa leitor pode interferir significativamente na qualidade da experiência de uso da mídia.

De modo geral, verificou-se que as decisões sobre os atributos da mídia envolvem dois desejos concorrentes entre si: a universalização da mídia para amplo grupo de estudantes versus o enriquecimento da mídia para torná-la mais atrativa. Para tornar a mídia atraente pode-se enriquecê-la com recursos variados (como vídeos e conteúdos interativos embarcados), mas quanto mais recursos forem inseridos, mais difícil se torna utilizar a mídia em dispositivos de menor capacidade de processamento e conectividade. Assim, decisões relacionadas ao desenho da mídia exigem harmonizar interesses concorrentes entre seu enriquecimento e seu uso mais universalizado por amplo grupo de estudantes. No caso da mídia implementada, os designers valorizaram mais sua simplificação e universalização, priorizando a escalabilidade esperada da iniciativa.

Quanto ao processo de desenvolvimento da mídia, os designers reforçaram sua percepção diagnosticada no primeiro ciclo de desenvolvimento, de que o processo de produção deve sofrer impactos devido à larga escala da produção. Contudo, concluiu-se que, à medida que as equipes técnicas se adaptarem a um novo processo, os impactos tendem a ser contornados.

Outra conclusão importante dos designers foi de que a adoção em larga escala exige novas competências e que é preciso promover a aprendizagem e capacitação das equipes de design para o novo contexto. 


\section{Avaliação e teste de soluções}

A entrega do livro eletrônico foi desenhada com a expectativa de promover seu uso espontâneo e não obrigatório, no próprio dispositivo do estudante. Mediante convite, buscou-se sensibilizar os estudantes para explorar o livro. Sua entrega foi previamente preparada no segundo ciclo de desenvolvimento, no qual decidiu-se inseri-lo no roteiro de estudos da disciplina e no repositório de recursos do AVA. Antes e durante a oferta foram desenvolvidas duas ações complementares para apoiar o uso do livro eletrônico: a) capacitação e acompanhamento dos tutores e b) publicação de vídeo de orientações para uso da mídia.

$\mathrm{Na}$ disciplina alvo cursaram 1.836 estudantes, dos quais 223 responderam ao questionário de avaliação, no qual coletou-se dados quantitativos e qualitativos. Essa coleta ocorreu após a oferta da disciplina, no período entre abril e junho de 2014. Entre os respondentes estavam tanto aqueles que utilizaram a mídia móvel (73 respondentes) quanto outros que optaram por não utilizá-la (150 respondentes). Os dados qualitativos foram submetidos aos mesmos procedimentos de análise de conteúdo já descritos anteriormente e os dados quantitativos foram tabulados e representados graficamente.

Destaca-se que o tamanho das amostras dos dados quantitativos é insuficiente para generalizar resultados baseando-se em procedimentos de validação estatística. Por isso, esses dados foram tomados como elementos contribuintes para a análise qualitativa, em uma estratégia interpretativa que tem por função mais levar à compreensão de características presentes no fenômeno em estudo do que a propor generalizações. Creswel (2007) chama esse processo de integração de tipos de dados, que corresponde à articulação de dados mistos (quantitativos e qualitativos) que, quando utilizados em conjunto, podem enriquecer a análise interpretativa e contribuir para demonstrar a convergência dos resultados.

Observou-se, entre todos os respondentes, diferentes posicionamentos em relação à iniciativa. Há os que a aplaudem, mas há também aqueles que apesar de apreciá-la preferem não mudar seus hábitos de estudo baseados nas mídias tradicionais (o livro impresso). As falas a seguir ilustram esses aspectos:

- Acredito que os dispositivos móveis só venham a acrescentar nos estudos.

- Ele [o livro eletrônico] ajuda bastante, mas acho ainda o livro impresso fundamental.

- Sugiro se possível que tenha a opção de imprimir caso haja necessidade.

Quanto aos benefícios do uso da mídia identificou-se manifestações que revelam a percepção de que o livro eletrônico é um recurso útil e que pode contribuir com o estudante: 
- Facilitam a vida do estudante, que durante as horas vagas, pode fazer uso destes em qualquer lugar.

- Acho uma boa ideia, principalmente se a pessoa está longe, consegue ficar conectada e estudando.

Nos dados quantitativos também pode-se observar indicadores dos benefícios. Entre os respondentes que utilizaram a mídia ofertada, 86\% consideraram que ela pode trazer facilidades aos estudos e $53 \%$ que ela pode promover a melhoria de seu desempenho. Mas nota-se também a presença de indivíduos que têm dúvidas sobre o aumento de esforços para usá-la (Figura 3).

Figura 3. Benefícios percebidos no uso do livro eletrônico

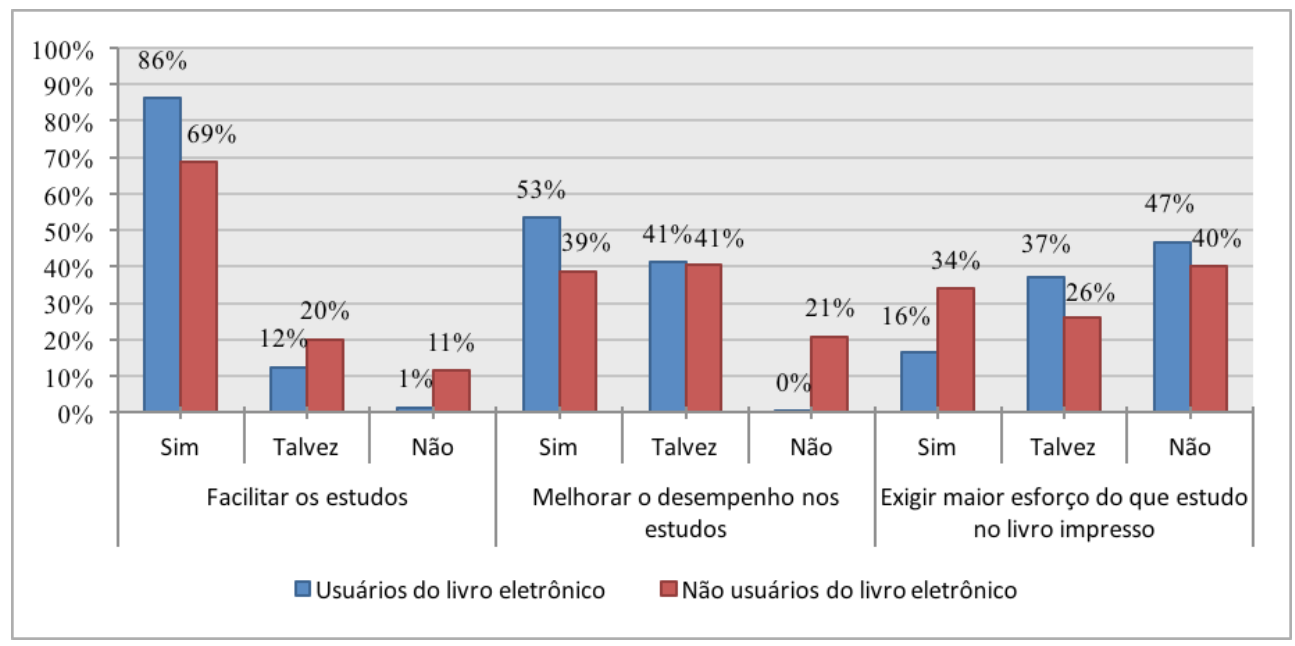

Diagnosticou-se também que há estudantes que são inexperientes no uso de livros para dispositivos móveis, conforme as falas:

- Nunca tinha lido qualquer livro utilizando esta ferramenta.

- A falta na verdade, se deve a minha pouca experiência com esse formato de estudo.

- Este dispositivo trás vantagens porém não costumo fazer uso desta ferramenta.

Em relação aos recursos do programa leitor, percebeu-se que há estudantes que o conhecem pouco. Observou-se depoimentos sobre ações consideradas impossíveis, mas que de fato estavam disponíveis, denotando desconhecimento de recursos do programa leitor: 
- Gosto muito de grifar nos livros e acrescentar alguma ideia, no dispositivo móvel não teria essa possibilidade.

- Impossibilidade de anotar.

- Gosto de iluminar as palavras chaves para melhor poder memorizar o conteúdo da disciplina.

Nos dados quantitativos (Figura 4) percebeu-se a pouca utilização dos recursos do programa leitor, corroborando os achados obtidos nos dados qualitativos que apontam a inexperiência de estudantes no uso de ebooks.

Figura 4. Uso dos recursos do programa leitor pelos estudantes que utilizaram a mídia móvel

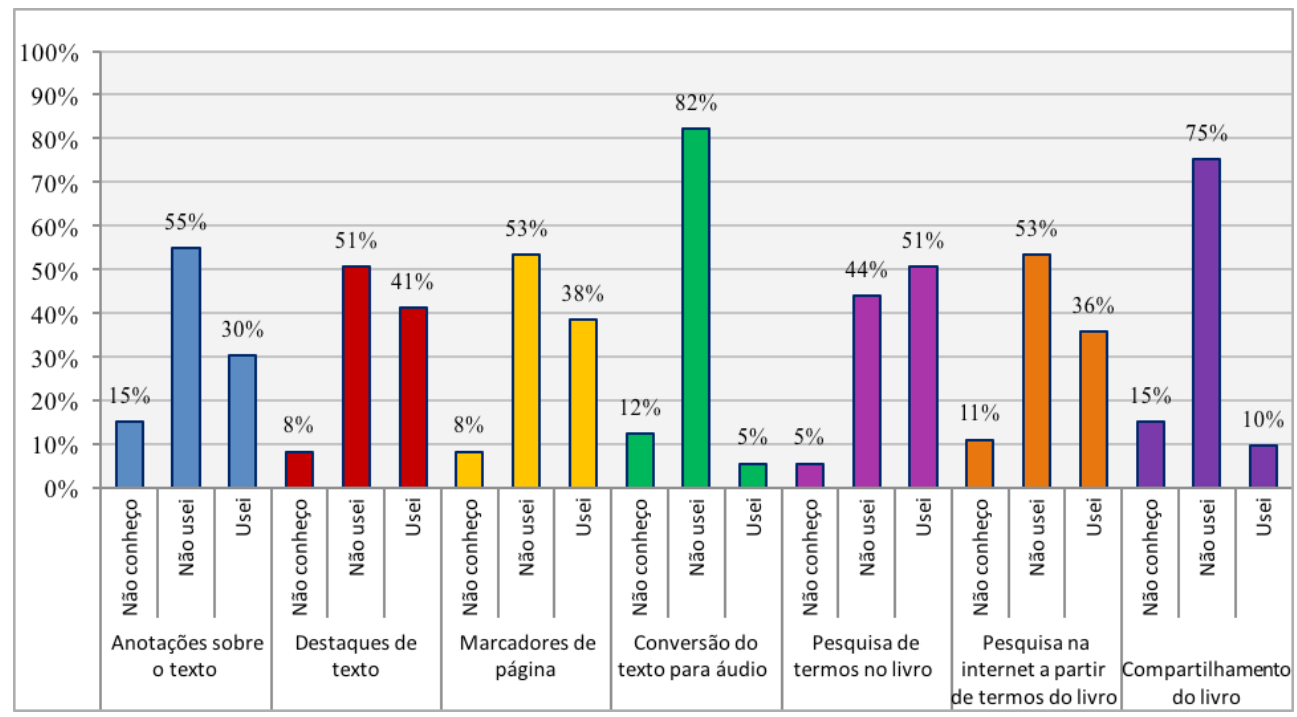

Do relato dos estudantes, nos dados qualitativos, extraiu-se suas dificuldades em relação à iniciativa, conforme o Quadro 2. 
Quadro 2. Principais dificuldades dos estudantes no uso da mídia móvel

\begin{tabular}{|l|}
\multicolumn{1}{|c|}{ Dificuldades dos estudantes } \\
\hline Conectividade do dispositivo é limitada \\
\hline Interface limitada causa desconforto \\
\hline Anotações no livro são difíceis \\
\hline Estudar pelo dispositivo móvel causa dispersão da atenção \\
\hline Dispositivo possui recursos de hardware limitados \\
\hline Desconhecimento no uso dos recursos do programa leitor \\
\hline Desigualdade entre recursos dos estudantes \\
\hline Dispositivos não são percebidos como recurso útil para estudar \\
\hline Custo de propriedade do dispositivo é alto \\
\hline
\end{tabular}

Entre as dificuldades pode-se identificar os três tipos de barreiras no uso de ebooks apresentadas por Girard (2014), que se referem às barreiras físicas do dispositivo, às barreiras cognitivas e às barreiras socioculturais decorrentes da falta de hábitos de estudar com esse tipo de recurso. Percebe-se que a variedade de dificuldades exige que a estratégia de implementação proponha caminhos de contorno dos obstáculos para que se possa promover a expansão da iniciativa. Parece igualmente importante promover mecanismos de apoio aos estudantes para que possam melhor incorporar as mídias móveis em seus estudos. Essas constatações reforçam o posicionamento dos especialistas, diagnosticados na primeira fase de desenvolvimento, de que a iniciativa pode enfrentar resistências.

\section{SOBRE RESULTADOS ENCONTRADOS E A ESCALABILIDADE}

Os resultados alcançados na pesquisa demonstram que a escalabilidade é fator determinante nas decisões da iniciativa. Para dar conta da expansão escalável, Wingkvist e Ericsson (2009) orientam que iniciativas de m-learning devem ser implementadas em estágios gradativos e sucessivos, em que o avanço para um próximo estagio só acontece quando houver resultados positivos e consolidados no estágio anterior. Dessa forma, segue-se um ciclo de vida de progressivo amadurecimento, que permite alcançar equilíbrio entre esforço demandado e resultados alcançados.

Nos resultados obtidos verificou-se também a presença de variados fatores organizacionais, educacionais e tecnológicos envolvidos. Segundo Passey (2010) a implementação em larga escala de m-learning passa por variados caminhos de implementação que se desenvolvem em paralelo. Por isso, sugere uma abordagem sistêmica, em que múltiplas ações, de variada natureza, aconteçam concomitantemente. Sugere também que as estratégias de implementação focalizem tanto os aspectos da aprendizagem quanto outros de natureza tecnológica, política e cultural. 
Nota-se, nos resultados, que há obstáculos e riscos a serem gerenciados, sobretudo as dificuldades dos estudantes. Sobre isso Passey (2010)orienta que é preciso prover em paralelo um suporte adequado e bem preparado, e que obstáculos podem ser superados por meio de uma liderança institucional positiva perante os estudantes para demonstrar os dispositivos como recursos legítimos para aprendizagem. Este direcionamento favorece a construção de uma nova cultura e promove comportamentos de aceitação de novos modos de aprender.

Essas orientações encontradas na literatura reforçam algumas das proposições obtidas dos especialistas e foram incorporadas aos princípios de design apresentados a seguir.

\section{O FRAMEWORK E OS PRINCÍPIOS DE DESIGN DESENVOLVIDOS}

A partir do processo de implementação vivenciado formulou-se o framework e os princípios de design. Segundo Reeves et al. (2005), é a reflexão sobre o processo de implementação que proporciona a revelação de princípios de design que podem subsidiar outros praticantes em futuros projetos. Na formulação dos princípios seguiu-se a orientação de Sandoval (2004), que sugere que esses sejam apresentados de modo genérico para que, quando utilizados, sejam interpretados e aplicados ao contexto particular de quem os utiliza. Desse modo, os princípios formulados referem-se às mídias móveis em geral.

Elaborou-se também um diagrama que representa as 'fases de implementação' e as 'perguntas direcionadoras' da iniciativa (Figura 5). A fases de implementação representam um possível caminho para a iniciativa. As perguntas direcionadoras correspondem a um conjunto de questionamentos que visam estimular a reflexão dos usuários do framework sobre aspectos importantes da implementação.

O framework é composto por três fases sequenciais, denominadas de: (a) delineamento e delimitação da implementação, (b) desenho e produção da mídia e (c) entrega e disseminação da mídia. Ao final da terceira fase setas retornam para as fases iniciais representando o desenvolvimento incremental da iniciativa. Fases e atividades são descritas a seguir. 
Figura 5. Diagrama do framework de implementação de mídias móveis em larga escala na $\mathrm{EAD}$

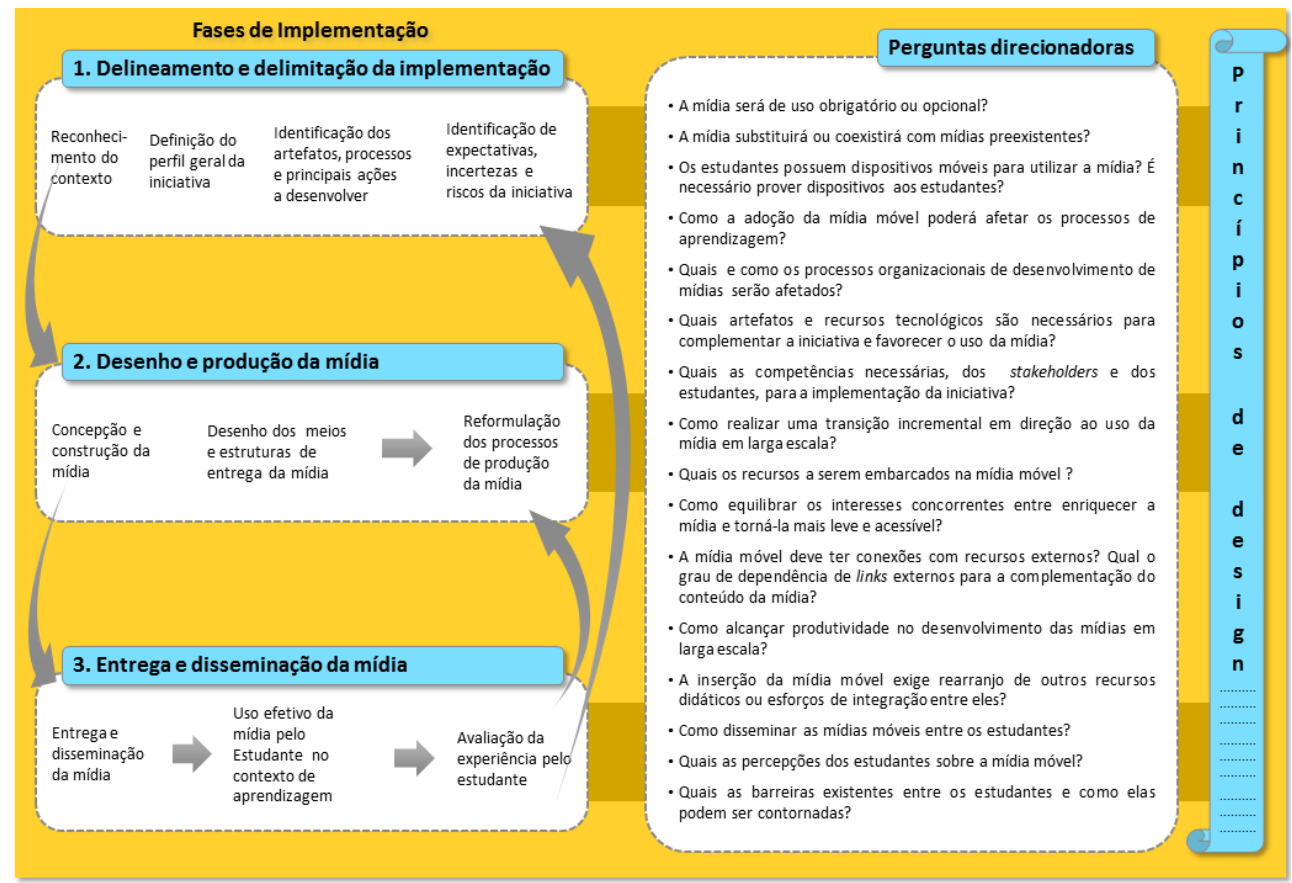

Fonte: Mulbert (2014)

\section{Fase 1: Delineamento e delimitação da implementação}

A primeira fase consiste nas primeiras decisões, por vezes críticas, que definem os contornos da iniciativa. Essas decisões dependem de interesses institucionais, dos benefícios e objetivos esperados e estão diretamente relacionadas ao contexto institucional e tecnológico da iniciativa. Outra ação importante dessa fase é identificar quais serão os processos organizacionais afetados e os artefatos tecnológicos envolvidos. Nessa fase pode haver várias incertezas que, ao serem reconhecidas, possibilitam o entendimento dos desafios e riscos a serem enfrentados posteriormente.

Alguns dos princípios de design formulados para essa primeira fase são sintetizados no Quadro 3. 
Quadro 3. Princípios de design para delineamento e delimitação da implementação de mídias móveis em larga escala - fase 1

\section{Princípios de design da fase 1}

A implementação de mídias móveis em larga escala é complexa devido ao amplo alcance que pretende atingir. Em pequena escala é um problema técnico de mais fácil domínio, em larga escala exige mudanças expressivas no entorno, ou seja, nos processos organizacionais, nas competências dos stakeholders e nos hábitos e rotinas dos estudantes. Essas ações exigem esforço e investimentos organizacionais proporcionais à escala almejada.

A delimitação da iniciativa envolve uma análise abrangente das possibilidades de implementação das mídias móveis no contexto institucional. Essa análise abrange a identificação de artefatos e tecnologias envolvidos, de processos organizacionais afetados e de ações e estratégias necessárias para implementação e disseminação da mídia.

\section{Fase 2: Desenho e produção da mídia}

Essa fase corresponde ao efetivo desenho dos atributos e limitações da mídia escolhida e de sua operacionalização e construção. As decisões de desenho da mídia móvel exigem reflexão para encontrar um desenho da mídia apropriado ao contexto da iniciativa. Concomitantemente é necessário definir como a mídia será entregue e quais são os mecanismos complementares necessários para alcançar o estudante. Além disso, a produção de uma nova mídia pode exigir reformulação ou criação de novos processos organizacionais. Essa fase envolve significativa aprendizagem dos profissionais envolvidos, que ao se mobilizarem para a construção da nova mídia amadurecem ideias, fazem experimentações e refletem sobre impactos em processos de trabalho.

Alguns dos princípios de design formulados para a segunda fase são sintetizados no Quadro 4.

Quadro 4. Princípios de design para desenho e produção de mídias móveis em larga escala fase 2

\section{Princípios de design da fase 2}

A implementação gradativa e incremental de mídias móveis tende a trazer maior segurança e controle às ações de implementação, pois facilita o tratamento progressivo de incertezas em direção à construção de bases sólidas e sustentáveis para alcançar larga escala.

O processo incremental de implementação em larga escala exige o gerenciamento de um período de transição em que a nova mídia vai sendo gradativamente ofertada até que alcance a escala esperada. A transição é necessária para que a instituição dê conta do alto volume de produção das novas mídias e para que a iniciativa se dissemine e supere gradativamente barreiras culturais. 


\section{Princípios de design da fase 2}

Decisões sobre o desenho da mídia envolvem o balanceamento de dois interesses concorrentes entre si: a universalização da mídia para amplo grupo de estudantes versus o enriquecimento da mídia para torná-la mais atrativa. Para tornar a mídia mais rica pode-se embarcar nela recursos variados, mas quanto mais recursos forem inseridos mais difícil pode se tornar seu uso em dispositivos de menor capacidade. Nesse caso, se os estudantes possuem dispositivos com potenciais variados, há o risco de perder a capacidade de atendêlos com equidade.

O uso da mídia móvel pode depender de outros artefatos ou recursos tecnológicos complementares que também precisam ser providos.

A adoção de mídias móveis em larga escala pode provocar impactos expressivos em processos organizacionais de suporte. Quando isso ocorre, torna-se necessário repensar a lógica de construção e distribuição dos conteúdos didáticos e buscar soluções que promovam a produtividade dos processos afetados.

\section{Fase 3: Entrega e disseminação da mídia}

A entrega da mídia consiste em sua inserção no ambiente de aprendizagem e no estímulo e apoio ao uso. Além da disponibilização da mídia, é necessário fazer sua disseminação por meio da orientação aos estudantes, assim como apoiá-los em caso de dificuldades. Esforços de disseminação devem promover a inserção de estímulos variados para mobilizar o estudante a incorporar a mídia em sua rotina de estudos. Assim, orientação e suporte ao estudante são atividades importantes a serem executadas ativamente pela instituição.

A avaliação da experiência dos estudantes é atividade potencialmente útil para orientar o enriquecimento da iniciativa. Compreender sua visão é fonte rica de subsídios para entender como o estudante se apropria da mídia, quais os benefícios que espera obter dela assim como os obstáculos que vivencia.

Alguns dos princípios de design formulados para essa terceira fase são sintetizados no Quadro 5.

Quadro 5. Princípios de design para a entrega e disseminação de mídias móveis em larga escala - fase 3

\section{Princípios de design da fase 3}

Os estudantes tendem a reconhecer que as mídias móveis podem ser um recurso útil para sua aprendizagem, mas quando as mídias móveis alteram suas rotinas de estudo ou rearranjam os recursos didáticos já conhecidos, esses podem a resistir à sua adoção. 


\section{Princípios de design da fase 3}

Mesmo que os estudantes estejam acostumados a usar mídias móveis em seu cotidiano, o uso educacional delas ainda não é bem compreendido por muitos deles. Por isso, a implementação precisa ser complementada com ações intensivas de disseminação da iniciativa que orientem e desenvolvam as competências estudantis para o uso avançado de mídias móveis em contextos de aprendizagem.

Os estudantes vivenciam vários tipos de barreiras para adoção das mídias educacionais móveis. Ações para minimizá-las ou contorna-las podem favorecer a escalabilidade. As principais barreiras são:

limitações físicas de seus dispositivos;

recursos limitados de conectividade de seu dispositivo;

alto custo de aquisição de dispositivos móveis mais potentes;

dificuldades cognitivas de atenção e concentração no estudo mediado por dispositivo

móvel;

falta de competências avançadas para uso das mídias móveis na aprendizagem;

modelos mentais e hábitos contrários ao uso de dispositivos móveis para atividades de aprendizagem.

Os estudantes são uma rica e importante fonte de subsídios para aperfeiçoar a iniciativa de implementação das mídias móveis. Por meio da compreensão de suas percepções e dificuldades pode-se identificar aspectos relevantes para o desenho e disseminação da iniciativa.

\section{CONSIDERAÇÕES FINAIS}

Este trabalho teve por objetivo desenvolver um conjunto de recomendações e princípios para a implementação e adoção de tecnologias móveis na EAD. Para isso adotou-se um processo de pesquisa, alinhado aos pressupostos da Design-Based Research.

O framework foi apresentado na forma de um diagrama com principais fases e atividades de implementação e de um conjunto de princípios de design que orientam a execução dessas fases, tendo como pano de fundo requisitos de escalabilidade com sustentabilidade. Os princípios de design representam conhecimento extraído da prática e são apresentados de forma genérica para que, ao serem utilizados, sejam interpretados e aplicados ao contexto particular de quem os utiliza.

Destaca-se que os resultados dessa pesquisa estão fortemente vinculados ao contexto em que foi realizada, ou seja, uma universidade comunitária brasileira, que possui uma particular configuração ambiental, determinada pelo perfil de seus profissionais e estudantes, pela cultura organizacional, por um modelo de EAD adotado, entre outros fatores. Isso estabelece um contexto específico, que envolve inúmeras variáveis, em um complexo ambiente que molda a iniciativa. Em cenários como esse a generalização de resultados apresenta-se como um desafio.

Segundo o grupo Design-Based Research Collective (2003), os métodos de testagem aleatória não são os mais apropriados para os contextos complexos da 
realidade educacional que a DBR pretende alcançar. Contextos educacionais reais costumam apresentar dezenas ou até centenas de variáveis interdependentes e isso faz com que estudos aleatórios não sejam apropriados para gerar generalizações. Segundo o grupo, a generalização nesse tipo de cenário pode ser obtida pela repetição de estudos em vários ambientes. Essa é a dinâmica preconizada pela Design-Based Research, de refinamento progressivo do conhecimento gerado por iniciativas fundadas no pragmatismo e na interação direta com o campo de investigação. Esse refinamento está, inclusive, previsto no processo de pesquisa da DBR adotado nesse estudo (Figura 1). Assim sendo, a continuidade natural para esse trabalho está em submeter o framework e os princípios de design formulados a novas intervenções, em busca de seu aperfeiçoamento e ampliação, em novos ciclos de investigação.

Destaca-se, por fim, que o caminho representado pelo framework proposto é um dos caminhos possíveis de implementação e não deve ser considerado como único.

\section{NOTAS}

1. EPUB corresponde ao formato de arquivo digital para ebooks, que representa conteúdos web em arquivo único. Possibilita produção e distribuição de uma publicação operável em múltiplas plataformas de hardware/software.

\section{REFERÊNCIAS BIBLIOGRÁFICAS}

Akçayir, M., Dündar, H., e Akçayir, G. (2016). What makes you a digital native? Is it enough to be born after 1980 ? Computers in Human Behavior, 6o, 435-440. Recuperado de http://doi.org/10.1016/j. chb.2016.02.089

Anderson, T., e Shattuck, J. (2012). Design-based research: a decade of progress in education research? Educational Researcher, 41(1), 16-25. Recuperado de http://doi. org/10.3102/0013189X11428813

Mülbert, A. L. (2014). A implementação de mídias em dispositivos móveis: um framework para a aplicação em larga escala e com sustentabilidade em educação a distância. Tese de Doutorado, Universidade Federal de Santa Catarina. Recuperado de http://www.bu.ufsc.br/ teses/PEGCo360-T.pdf

Barab, S., e Squire, K. (2004). Design-based research : putting a stake in the ground.
The Journal of the Learning Sciences, 13(1), 1-14. Recuperado de http://www. tandfonline.com/doi/abs/10.1207/ s15327809jls1301 1

Creswell, J. W. (2007). Projeto de pesquisa: métodos qualitativo, quantitativo $e$ misto. Porto Alegre: Artmed.

Design-Based Research Collective. (2003). Design-based research: an emerging paradigm for educational inquiry. Educational Researcher, 32(1), 5-8. Recuperado de http://www. designbasedresearch.org/reppubs/ DBRC2003.pdf

Friese, S. (2013). ATLAS.ti 7: User Guide and Reference. Berlin: ATLAS.ti Scientific Software Development.

Girard,A.(2014). Reader's block: a systematic review of barriers to adoption, access and use in e-book user studies. Information Research, 19(2). Recuperado de http:// informationr.net/ir/19-2/paper624.html 
Hutchison, M., Tin, T., e Cao, Y. (2008). "Inyour-pocket" and "on-the-fly": meeting the needs of today's new generation of online learners with mobile learning technology. In T. Anderson (Ed.), The theory and practice of online learning (pp. 201-20). Edmonton: Athabasca University. Recuperado de http://www. aupress.ca/index.php/books/120146

Jones, C., Ramanau, R., Cross, S., e Healing, G. (2010). Net generation or digital natives: is there a distinct new generation entering university? Computers \& Education, 54(3), 722-732. Recuperado de http:// doi.org/10.1016/j.compedu.2009.09.022

Matta, A. E. R., Silva, F. P. S., e Boaventura, E. M. (2014). Design-based research ou pesquisa de desenvolvimento: metodologia para pesquisa aplicada de inovação em educação do século XXI. Revista da FAEEBA: Educação E Contemporaneidade, 23(42), 23-36. Recuperado de http://www.revistas.uneb. br/index.php/faeeba/article/view/1025

Mülbert, A. L. (2014). A implementação de mídias em dispositivos móveis: um framework para a aplicação em larga escala e com sustentabilidade em educação a distância. Tese de Doutorado, Universidade Federal de Santa Catarina. Recuperado de http://www.bu.ufsc.br/ teses/PEGCo360-T.pdf

New Media Consortium. (2016). Horizon Report 2016 Higher Education. Austin, Texas: The New Media Consortium. Recuperado de http://cdn.nmc.org/ media/2015-nmc-horizon-report-HEEN.pdf

Passey, D. (2010). Mobile learning in school contexts: can teachers alone make it happen? IEEE Transactions on Learning Technologies, 3(1), 68-81.
Reeves, T. C. (2000). Enhancing the worth of instructional technology research through 'design experiments' and other development research strategies. In International Perspectives on Instructional Technology Research for the 21st Century. New Orleans: American Educational Research Association.

Reeves, T. C., Herrington, J., e Oliver, R. (2005). Design research: a socially responsible approach to instructional technology research in higher education. Journal of Computing in Higher Education, 16(2), 96-115. Recuperado de http://link.springer.com/ article/10.1007/BF02961476

Sandoval, W. (2004). Developing Learning Theory by Refining Conjectures Embodied in Educational Designs. Educational Psychologist, 39(4), 213-223.

Santaella, L. (2013). A ecologia pluralista da comunicação: conectividade, mobilidade e ubiquidade. São Paulo: Paulus.

Traxler, J., e Vosloo, S. (2014). Introduction: the prospects for mobile learning. Prospects, 44(1), 13-28. Recuperado de http://doi.org/10.1007/s11125-0149296-Z

Wang, F., e Hannafin, M. J. (2005). Designbased research and technology-enhanced learning environments. Educational Technology Research and Development, 53(4), 5-23.

Wingkvist, A., e Ericsson, M. (2009). A meta-model describing the development process of mobile learning. In R. W. H. Spaniol, M. Li, Q. Klamma y R. Lau (Ed.), Proceedings of the 8th International Conference on Web-Based Learning (pp. 454-463). Aachen, Germany: SpringerVerlag. 


\section{PERFIL ACADÊMICO E PROFESIONAL DOS AUTORES}

Ana Luisa Mulbert. Doutora em Engenharia e Gestão do Conhecimento, Mestre em Administração, Graduada em Ciências da Computação e em Pedagogia. É professora na Universidade do Sul de Santa Catarina (UNISUL). Pesquisa sobre Tecnologias Educacionais, Ambientes Virtuais de Aprendizagem e Educação a Distância.

E-mail: amulbert@gmail.com

\section{ENDEREÇO DA AUTORA}

Universidade do Sul de Santa Catarina - Campus Virtual

Av. Pedra Branca, 25, Cidade Universitária

Palhoça, SC - Brasil.

Alice Theresinha Cybis Pereira. Graduada em Arquitetura e Urbanismo,Doutora em Arquitetura.Éprofessora da Universidade Federal de Santa Catarina.Atua nas áreas: Ambientes Virtuais de Aprendizagem, Objetos Hipermídia de Aprendizagem, Educação a Distância, entre outras. E-mail: acybis@gmail.com

\section{ENDEREÇO DA AUTORA}

Universidade Federal de Santa Catarina

Centro de Comunicação e Expressão - sl. 127

Florianópolis, SC - Brasil

Data de recebimento do artigo: $08 / 12 / 2016$

Data de aceitação do artigo: 09/02/2017

\section{Como citar ese artigo:}

Mulbert, A. L., y Pereira, A. T. C. (2017). Implementação de mídias em dispositivos móveis: um framework de aplicação em grande escala na educação a distância. RIED. Revista Iberoamericana de Educación a Distancia, 2O(2), pp. 233254. doi: http://dx.doi.org/10.5944/ried.20.2.17673 